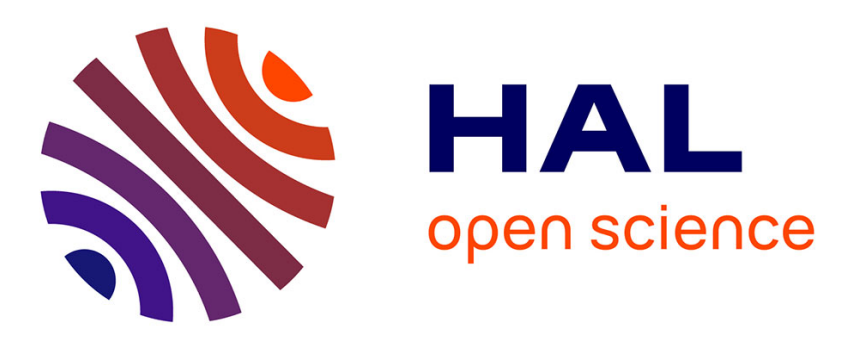

\title{
Hypervelocity impact on CFRP: testing, material modelling, and numerical simulation
}

\author{
M. Wicklein, S. Ryan, D.M. White, R.A. Clegg
}

\section{To cite this version:}

M. Wicklein, S. Ryan, D.M. White, R.A. Clegg. Hypervelocity impact on CFRP: testing, material modelling, and numerical simulation. International Journal of Impact Engineering, 2008, 35 (12), pp.1861. 10.1016/j.ijimpeng.2008.07.015 . hal-00542562

\section{HAL Id: hal-00542562 https://hal.science/hal-00542562}

Submitted on 3 Dec 2010

HAL is a multi-disciplinary open access archive for the deposit and dissemination of scientific research documents, whether they are published or not. The documents may come from teaching and research institutions in France or abroad, or from public or private research centers.
L'archive ouverte pluridisciplinaire HAL, est destinée au dépôt et à la diffusion de documents scientifiques de niveau recherche, publiés ou non, émanant des établissements d'enseignement et de recherche français ou étrangers, des laboratoires publics ou privés. 


\section{Accepted Manuscript}

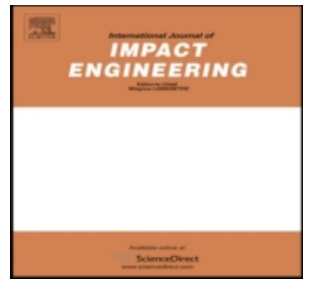

Title: Hypervelocity impact on CFRP: testing, material modelling, and numerical simulation

Authors: M. Wicklein, S. Ryan, D.M. White, R.A. Clegg

PII: $\quad$ S0734-743X(08)00171-1

DOI: $\quad$ 10.1016/j.ijimpeng.2008.07.015

Reference: IE 1653

To appear in: International Journal of Impact Engineering

Received Date:

Revised Date:

Accepted Date:

Please cite this article as: Wicklein M, Ryan S, White DM, Clegg RA. Hypervelocity impact on CFRP: testing, material modelling, and numerical simulation, International Journal of Impact Engineering (2008), doi: 10.1016/j.ijimpeng.2008.07.015

This is a PDF file of an unedited manuscript that has been accepted for publication. As a service to our customers we are providing this early version of the manuscript. The manuscript will undergo copyediting, typesetting, and review of the resulting proof before it is published in its final form. Please note that during the production process errors may be discovered which could affect the content, and all legal disclaimers that apply to the journal pertain. 


\title{
Hypervelocity impact on CFRP: testing, material modelling, and numerical simulation
}

\author{
M. Wicklein ${ }^{\mathrm{a}, *}$, S. Ryan ${ }^{\mathrm{a}}$, D.M. White ${ }^{\mathrm{b}}$, R.A. Clegg \\ ${ }^{a}$ Fraunhofer Ernst-Mach-Institut, Eckerstrasse 4, 79104 Freiburg, Germany \\ ${ }^{b}$ Century Dynamics Ltd., Suite 1, 3 Horsham Gates, North Street, Horsham, West Sussex, RH13 5PJ, England
}

\begin{abstract}
This paper describes the derivation and validation of a numerical material model that predicts the highly dynamic behaviour of CFRP (carbon fibre reinforced plastic) under hypervelocity impact. CFRP is widely used in satellites as face sheet material in $\mathrm{CFRP}-\mathrm{Al} / \mathrm{HC}$ sandwich structures (HC = honeycomb), that can be exposed to space debris. A review of CFRP-Al/HC structures typically used in space was performed. Based on this review, a representative structure in terms of materials and geometry was selected for study in the work described here. An experimental procedure for the characterisation of composite materials is documented in [1]. The test results from the CFRP of the current study allow for the derivation of an experimentally based orthotropic continuum material model data set that is capable of predicting the mechanical behaviour of CFRP under hypervelocity impact. Such a data set was not previously available. In [2] an orthotropic material data set was used for modelling HVI on AFRP (aramid fibre reinforced plastic), which shows relatively high deformability before failure. The enhancements of the modelling approaches in [1] and [3] necessary to model brittle CFRP are specified. An experimental hypervelocity impact campaign was performed at two different two stage light gas guns which encompassed both normal and oblique impacts for a range of impact velocities and projectile diameters. Validation of the numerical model is provided through comparison with the experimental results. For that purpose measurements of the visible damage of the face sheets and of the HC core are conducted. In addition, the numerically predicted damage within the CFRP is compared to the delamination areas found in ultrasonic scans.
\end{abstract}

Keywords: Hypervelocity; Impact; CFRP; Material model; Simulation

\section{Introduction}

The share of composite materials in aerospace structures has increased drastically in the last decades due to the low weight and high stiffness of such materials. These properties are particularly attractive for space applications. Today, a typical satellite wall is a sandwich component consisting of CFRP face sheets and an aluminium honeycomb core. In contrast to manned space missions, no

${ }^{*}$ Corresponding author. Tel.: +49 7612714 356; Fax: +49 76127141356

E-mail address: wicklein@emi.fhg.de 
additional protection shields are applied for unmanned satellites. Thus, in order to assess the risk posed by the impact of space debris on the survivability of the mission, it is important to understand the performance of CFRP during HVI. This study presents theoretical, experimental, and numerical results that help to understand these issues. In many missions, CFRP-Al/HC is covered by MLI (multi layer insulation) to control the thermal environment of the spacecraft. The mechanical behaviour of MLI under HVI and its influence on the impact process was also investigated and is presented in a separate paper [4].

HVI on fibre reinforced composites is discussed in the literature from different points of view: White et al. [5] reported the numerical simulation and experimental characterisation of CFRP. They derived a data set that allows for the numerical simulation of HVI using the material modelling approach presented in [3]. The impact of steel projectiles on graphite/epoxy laminates was simulated by Chen et al [6]. The authors used an orthotropic elastic-plastic strength model that was not based on experimental characterisation but rather on micromechanical simulations. It was stated that the SPH method (smooth particles hydrodynamics) is a suitable numerical approach to simulate such impact events. Riedel et al. [7] studied the impacts on CFRP aircraft wing components from fragmenting warheads. From non-destructive ultrasonic tests of the impacted CFRP it was concluded that the numerical simulations of the impact underestimated the extent of delamination. The impact of $4 \mathrm{~mm}$ steel spheres on CFRP for velocities up to $1230 \mathrm{~m} / \mathrm{s}$ was investigated by Fujii et al. [8], however the projectile size and density as well as the velocities are not representative of space debris. Thissell et al. [9] loaded CFRP compressively at strain rates up to 2000 1/s. The results revealed a significant rate dependence of the stress strain behaviour. The diameter and velocity of a projectile impacting on CFRP were varied by Nagao et al. [10]. The resulting delamination was quantified by means of ultrasonic scans and X-ray computer tomography. Shintate and Sekine [11] investigated the influence of the laminate stacking sequence and impact angle on the debris cloud generated from HVI on graphite/epoxy laminates. It was observed that the formation of the debris cloud depends on the impact angle, however the effect of stacking was found to be negligible.

The impact on CFRP-Al/HC is also addressed in the literature, e. g. Taylor at al. [12]. Schaefer and Ryan [13] conducted numerous HVI tests on different sandwich configurations with varying projectile sizes, velocities, and impact angles. They derived the so-called 'SRL ballistic limit equation', which is universally applicable for CFRP-Al/HC structures. Ryan et al. [14] examined the influence of the impact location with regards to the honeycomb core numerically. While there was a dependence of the fragment dispersion, the ballistic limit was not affected.

The theoretical modelling and numerical simulation of orthotropic materials under HVI loading is a challenging task. For an orthotropic material, an isotropic strain field does not result in an isotropic stress field and vice versa. Thus, the separation of the material behaviour into a volumetric and deviatoric part - as usually done in numerical codes for impact simulations - is not possible. Anderson et al. [15] provided a methodology for coupling the anisotropic material stiffness and strength with shock effects and associated energy dependence. This approach was the basis for the material model implemented in [1]. When a composite material shows non-linear stress-strain behaviour and inelastic deformation, this must be taken into account with an adequate plasticity model. For composites 'plasticity' can also mean development of cracks or delamination on the microscale, which is observed on the macroscale simply as irreversible deformation. Chen et al. [16] presented a general quadratic yield function applicable for orthotropic composites. This plasticity model and an additional orthotropic softening description were implemented in [1]. While the focus in [1] and [3] was on protection 
materials with high deformability and low strength, this paper concentrates on a high performance structural composite with low deformability and high strength. The aim was to establish a material model data set for CFRP that predicts the mechanical behaviour under HVI. Figure 1 summarizes the procedure of the model development and validation. A spacecraft representative CFRP is chosen, characterized, and tested under impact. From the characterization data, a material model is set up that is used for simulating the impact tests, which provide the validation basis.

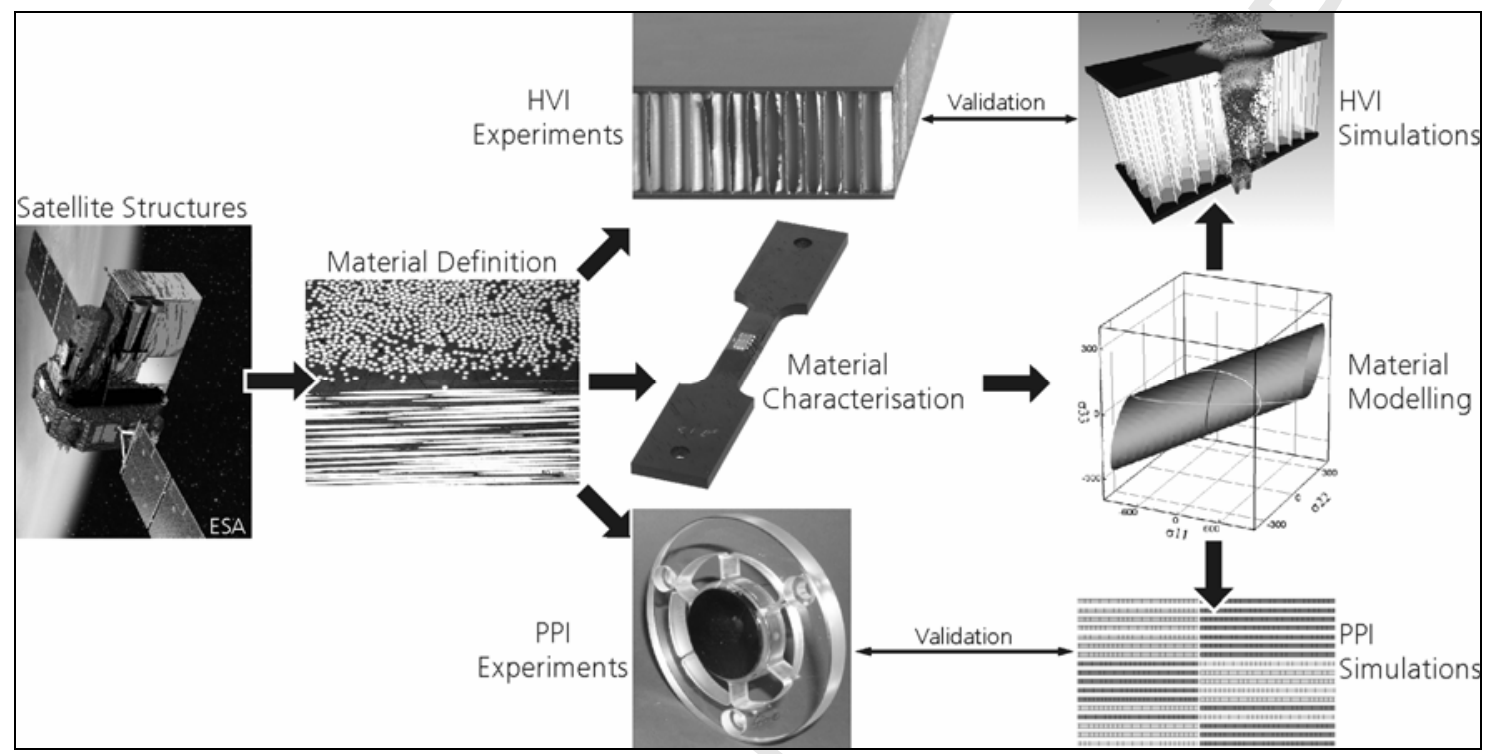

Fig. 1. Flow-chart of this study.

\section{Material Definition}

In order to investigate a representative sandwich structure, actual satellite walls have been analysed in terms of sandwich geometry and fibre properties (Fig. 2). Besides these parameters, care was taken to select a structure that is also representative in terms of fibre volume, resin system, lay-up, manufacturing process, cell size and material of the honeycombs. Most of the CFRP face sheets in Fig. 2 are thinner than $1.5 \mathrm{~mm}$, which makes many characterisation tests impossible. Therefore, a manufacturer was chosen that could deliver representative CFRP both as thin face sheets as part of a honeycomb sandwich panel for HVI tests and as $6 \mathrm{~mm}$ thick plates used for characterisation. This thickness is recommended to conduct, for example, through thickness strain measurements or planar plate impact spallation. The sandwich and fibre data is included in Fig. 2 ('this study'). The material is shown in Fig. 3. In the micrographs the fibres appear bright and the matrix dark. The different crosssections of the fibres are a result of the stacking sequence. Due to an autoclave manufacturing process, the CFRP offers high quality without any porosity. The technical data of the sandwiches is documented in Table 1 . The $0^{\circ}$ - and $90^{\circ}$-orientations of the laminate are defined as the 1- and 2-directions in the material characterisation and modelling, respectively. The lay-up was selected such that no fibres were aligned at $90^{\circ}$. This results in an orthotropic composite with a high degree of anisotropy and allows plastic deformation to occur under loading in this direction. 
Wicklein, et al. / International Journal of Impact Engineering
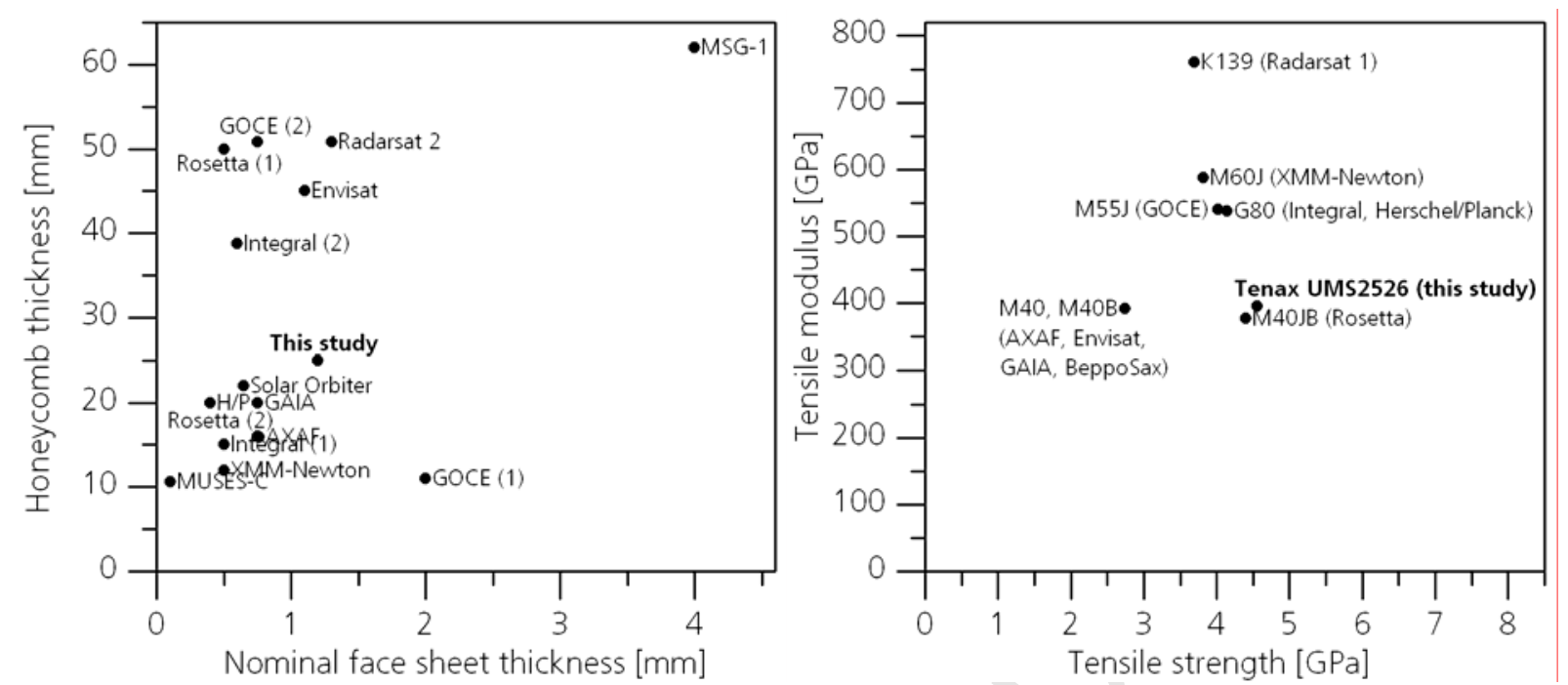

Fig. 2. Sandwich geometry (left) and fibre properties (right) of this study compared to actual space missions. Some of the data is from Faraud and Destefanis [17].

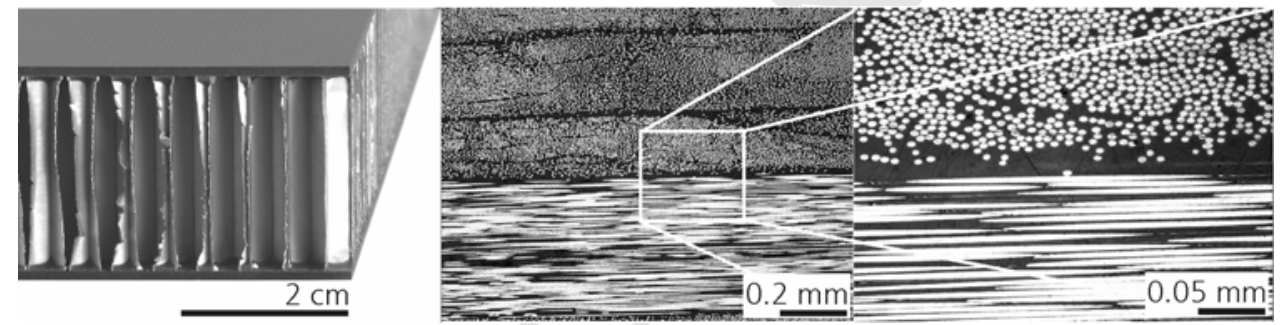

Fig. 3. Structure investigated in this study. Left: Photograph of the CFRP-Al/HC. Middle and right: Micrographs of the CFRP face sheets.

Table 1. Properties of the investigated CFRP-Al/HC.

\begin{tabular}{ll}
\hline Property & Value / description \\
\hline Fibre type & Tenax UMS2526 \\
Fibre tensile modulus & $395 \mathrm{GPa}$ \\
Fibre tensile strength & $4.56 \mathrm{GPa}$ \\
Fibre density & $1.79 \mathrm{~g} / \mathrm{cm}^{3}$ \\
Fibre volume in CFRP & $52 \%$ \\
Single ply & Krempel MUDB 2006 \\
Matrix & Krempel BD System $120^{\circ} \mathrm{C}$ epoxy resin \\
HC type & Hexcel CRIII-3/16-5056-0.0007 \\
HC thickness & $25 \mathrm{~mm}$ \\
Face sheet thickness & $1.37 \mathrm{~mm}$ \\
Lay-up & $0 / 45 /-45 /-45 / 45 / 0$ \\
Orientation CFRP $\leftrightarrow$ HC & Cell size direction $=90^{\circ}$ \\
\hline
\end{tabular}

Both guarantee the most general case for validating the numerical material models. 
Wicklein, et al. / International Journal of Impact Engineering

\section{Material Characterization}

Riedel et al. [1] report a testing procedure applicable to characterise composite materials for HVI events. Details of this approach are not given here.

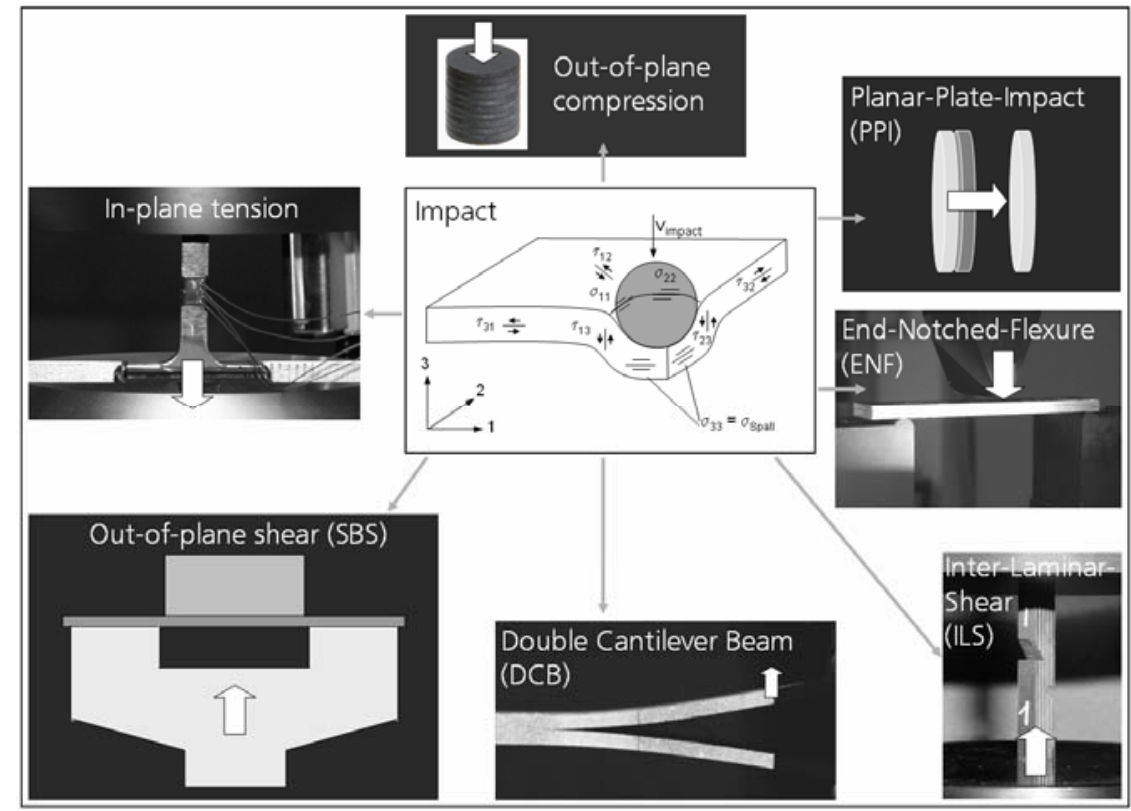

Fig. 4. Illustration of the conducted characterisation tests. The sketch in the middle demonstrates how the CFRP can be loaded under many different stress states at the same time when impacted.

Table 2. CFRP characterization experiments. The types of parameters that can be determined with these tests are shown in the right column.

\begin{tabular}{|c|c|c|c|}
\hline Test type & $\begin{array}{c}\text { Specimen size } \\
{[\mathrm{mm}]}\end{array}$ & $\begin{array}{l}\text { Number } \\
\text { of tests }\end{array}$ & Model parameters \\
\hline Out-of-plane compression & $\varnothing=6$, height $=6$ & 3 & Orthotropic elasticity constants \\
\hline $\begin{array}{l}\text { In-plane tension at } 0^{\circ}, 45^{\circ} \text {, and } \\
90^{\circ}\end{array}$ & $\begin{array}{l}40 \times 10 \times 6 \\
\text { (in parallel part of } \\
\text { sample) }\end{array}$ & 22 & $\begin{array}{l}\text { Orthotropic elasticity constants, } \\
\text { Orthotropic plasticity coefficients, } \\
\text { Hardening master curve, } \\
\text { Failure stresses, } \\
\text { Fracture energies }\end{array}$ \\
\hline Out-of-plane shear at $0^{\circ}, 90^{\circ}$ & $140 \times 20 \times 6$ & 8 & Orthotropic elasticity constants \\
\hline Double cantil. beam at $0^{\circ}, 90^{\circ}$ & $250 \times 25 \times 6$ & 7 & Fracture energies \\
\hline Inter-laminar shear & $40 \times 6 \times 6$ & 9 & Failure stresses \\
\hline End-notched flexure & $120 \times 25 \times 6$ & 8 & Fracture energies \\
\hline Planar plate impact & $\begin{array}{l}\varnothing=50, \\
\text { height }=1-6\end{array}$ & 17 & $\begin{array}{l}\text { Failure stresses, } \\
\text { Equation of state }\end{array}$ \\
\hline
\end{tabular}

Specifications for certain test types can also be found in the literature elsewhere. The tests performed on the material defined in section 2 are summarized graphically in Fig. 4. The complete 
Wicklein, et al. / International Journal of Impact Engineering

characterization is documented in [18]. In addition to the procedure in [1], out-of-plane compression tests were executed to determine the through thickness Young's modulus. Table 2 gives an overview of the material tests. The results of these characterisation tests are the input for the material model, which is presented in the next chapter.

\section{Material Modelling}

The data set derived in this paper can be used for the material models reported in [1] and [3]. The procedures for deriving most of the material constants are given in [1] and [3]. The focus of this chapter is on the derivation of the plasticity parameters and on the presentation of the complete material model. The modelling approach presented in the following applies a 3D continuum material model to be used with finite volume elements or SPH particles within the software ANSYS ${ }^{\circledR}$ AUTODYN $^{\circledR}$. Using shell elements to model CFRP under HVI would not allow the accurate prediction of shock waves propagating through the thickness of the laminate. In this paper the individual plies are not modelled explicitly, rather the laminate is represented by a homogenised orthotropic material. The elastic deformations are modelled with a linear relationship between stresses and strains introducing nine elastic constants:

$$
\left[\begin{array}{l}
\varepsilon_{1} \\
\varepsilon_{2} \\
\varepsilon_{3} \\
\gamma_{4} \\
\gamma_{5} \\
\gamma_{6}
\end{array}\right]=\left[\begin{array}{cccccc}
\frac{1}{E_{11}} & \frac{-v_{21}}{E_{22}} & \frac{-v_{31}}{E_{33}} & 0 & 0 & 0 \\
\frac{-v_{12}}{E_{11}} & \frac{1}{E_{22}} & \frac{-v_{32}}{E_{33}} & 0 & 0 & 0 \\
\frac{-v_{13}}{E_{11}} & \frac{-v_{23}}{E_{22}} & \frac{1}{E_{33}} & 0 & 0 & 0 \\
0 & 0 & 0 & \frac{1}{G_{23}} & 0 & 0 \\
0 & 0 & 0 & 0 & \frac{1}{G_{13}} & 0 \\
0 & 0 & 0 & 0 & 0 & \frac{1}{G_{12}}
\end{array}\right]\left[\begin{array}{c}
\sigma_{1} \\
\sigma_{2} \\
\sigma_{3} \\
\tau_{4} \\
\tau_{5} \\
\tau_{6}
\end{array}\right]
$$

A polynomial EOS (equation of state) describes the volumetric response:

$$
\begin{array}{ll}
\mathrm{p}=\mathrm{A}_{1} \mu+\mathrm{A}_{2} \mu^{2}+\mathrm{A}_{3} \mu^{3}+\left(\mathrm{B}_{0}+\mathrm{B}_{1} \mu\right) \rho_{0} \mathrm{e} & (\mu \geq 0) \\
\mathrm{p}=\mathrm{T}_{1} \mu+\mathrm{T}_{2} \mu^{2}+\mathrm{B}_{0} \rho_{0} \mathrm{e} & (\mu<0)
\end{array}
$$

The density and internal energy are given by $\rho$ and e, respectively. $A_{1}, A_{2}, A_{3}, B_{0}, B_{1}, T_{1}$, and $T_{2}$ are material constants and $\mathrm{p}$ is the hydrostatic pressure. The constant $\mathrm{A}_{1}$ is the effective bulk modulus, 
which depends on the elastic Poisson ratios and Young's moduli. Thus, $\mathrm{A}_{1}$ can not be specified independently from the stiffness matrix. As a consequence, the final material model should also be validated by simulating the PPI (planar plate impact) experiments (see section 5). For that reason the PPI tests are not only characterisation tests (derivation of spallation strength) but also important validation tests. The coupling of the orthotropic stiffness matrix and the volumetric response is based on the work by Anderson et al. [15]. The polynomial EOS for the volumetric response was chosen as it is more flexible for modelling than a shock EOS. It is assumed that $A_{1}=T_{1}$ and $A_{2}=T_{2}$.

Plastic deformations occurred when the material was loaded under uniaxial tension in the 2direction. To model this plasticity, the quadratic yield function by Chen et al. [16] was used together with an associated flow rule:

$$
\begin{aligned}
& \mathrm{f}\left(\sigma_{\mathrm{ij}}\right)=\mathrm{a}_{11} \sigma_{11}^{2}+\mathrm{a}_{22} \sigma_{22}^{2}+\mathrm{a}_{33} \sigma_{33}^{2}+ \\
& +2 \mathrm{a}_{12} \sigma_{11} \sigma_{22}+2 \mathrm{a}_{23} \sigma_{22} \sigma_{33}+2 \mathrm{a}_{13} \sigma_{11} \sigma_{33}+ \\
& +2 \mathrm{a}_{44} \sigma_{23}^{2}+2 \mathrm{a}_{55} \sigma_{31}^{2}+2 \mathrm{a}_{66} \sigma_{12}^{2}=\mathrm{k}
\end{aligned}
$$

The shape and size of the yield surface are defined by the nine plasticity coefficients $\mathrm{a}_{\mathrm{ij}}$ and the hardening parameter $\mathrm{k}$, respectively. The plasticity coefficients are assumed to be constant. Thus, only isotropic hardening can be modelled, as the shape of the yield surface cannot change - only its size. The hardening of the material is described by means of one single master curve. In general any of the three normal or three shear stress-strain responses can be used. In this study the largest plastic deformation was found under tension in the 2-direction. Therefore, the master curve $\bar{\sigma}\left(\bar{\varepsilon}^{p}\right)$ was defined from the results of the $90^{\circ}$-tension tests, and $\mathrm{a}_{22}$ can be set to 1 without loss of generality. The effective stress $\bar{\sigma}$ and the effective plastic strain $\bar{\varepsilon}^{\mathrm{p}}$ must be calculated from $\sigma_{22}$ and $\varepsilon_{22}$ from the $90^{\circ}$-tension test:

$$
\bar{\sigma} \equiv \sqrt{\frac{3}{2} \mathrm{f}}=\sqrt{\frac{3}{2}} \sigma_{22} \quad \text { and } \quad \bar{\varepsilon}^{\mathrm{p}}=\sqrt{\frac{2}{3}} \varepsilon_{22}^{\mathrm{p}} \quad \text { with } \quad \varepsilon_{22}^{\mathrm{p}}=\varepsilon_{22}-\frac{\sigma_{22}}{\mathrm{E}_{22}}
$$

In the model, the master curve is approximated by a piecewise linear curve featuring ten stressstrain data points. The remaining plasticity parameters can be derived from the measured plastic Poisson numbers (see [16] and [2]), and analyzing certain loading cases in terms of plasticity. For example, no plastic deformations were observed in the 1-direction until failure. Thus, it must be guaranteed, that the effective stress associated with the failure stress $\sigma_{11 \text {,fail }}$ is not larger than the first effective stress of the master curve $\bar{\sigma}_{\# 1}$. Otherwise plasticity would be predicted before failure. Thus, $\mathrm{a}_{11}$ must fulfil:

$$
\bar{\sigma}_{\# 1} \geq \sqrt{\frac{3 \mathrm{a}_{11}}{2}} \sigma_{11, \text { fail }}
$$

Restrictions must be imposed on the parameters of the yield surface to ensure the stability of the Backward-Euler return algorithm. Such restrictions are also known for other models, e. g. Hill or TsaiWu. For the quadratic yield function used here stability could be gained by ensuring that the yield 
surface in normal stress space forms a real closed ellipsoid, i. e. Det $E<0$, rank e $=3$, rank $E=4$, and all non-zero roots of e have the same sign. In these equations we have:

$$
\mathrm{E}=\left[\begin{array}{cccc}
\mathrm{a}_{11} & \mathrm{a}_{12} & \mathrm{a}_{13} & 0 \\
\mathrm{a}_{12} & \mathrm{a}_{22} & \mathrm{a}_{23} & 0 \\
\mathrm{a}_{13} & \mathrm{a}_{23} & \mathrm{a}_{33} & 0 \\
0 & 0 & 0 & -\mathrm{k}
\end{array}\right] \quad \text { and } \quad \mathrm{e}=\left[\begin{array}{ccc}
\mathrm{a}_{11} & \mathrm{a}_{12} & \mathrm{a}_{13} \\
\mathrm{a}_{12} & \mathrm{a}_{22} & \mathrm{a}_{23} \\
\mathrm{a}_{13} & \mathrm{a}_{23} & \mathrm{a}_{33}
\end{array}\right]
$$

These stability conditions could only be fulfilled by changing the plasticity parameters derived from the tests. The task was to find the data set $\mathrm{a}_{\mathrm{ij}}$, that is 'closest' to the experimental values $\mathrm{a}_{\mathrm{ij}, \exp }$ and fulfils the above equations. This can be treated as a minimisation problem:

$$
\mathrm{d}=\sqrt{\sum_{\mathrm{ij}}\left(\mathrm{a}_{\mathrm{ij}}-\mathrm{a}_{\mathrm{ij}, \exp }\right)^{2}} \stackrel{!}{=} \min
$$

For this optimisation additional boundary conditions must be kept in mind, e. g. a plasticity parameter that would predict lateral contraction under compressive loading instead of an experimentally observed expansion should be rejected. The optimum data set $(d=0.654)$ was found numerically by scanning the whole parameter space with a resolution of 0.0025 . The yield surfaces obtained with the final plasticity parameters are shown in Fig. 5.
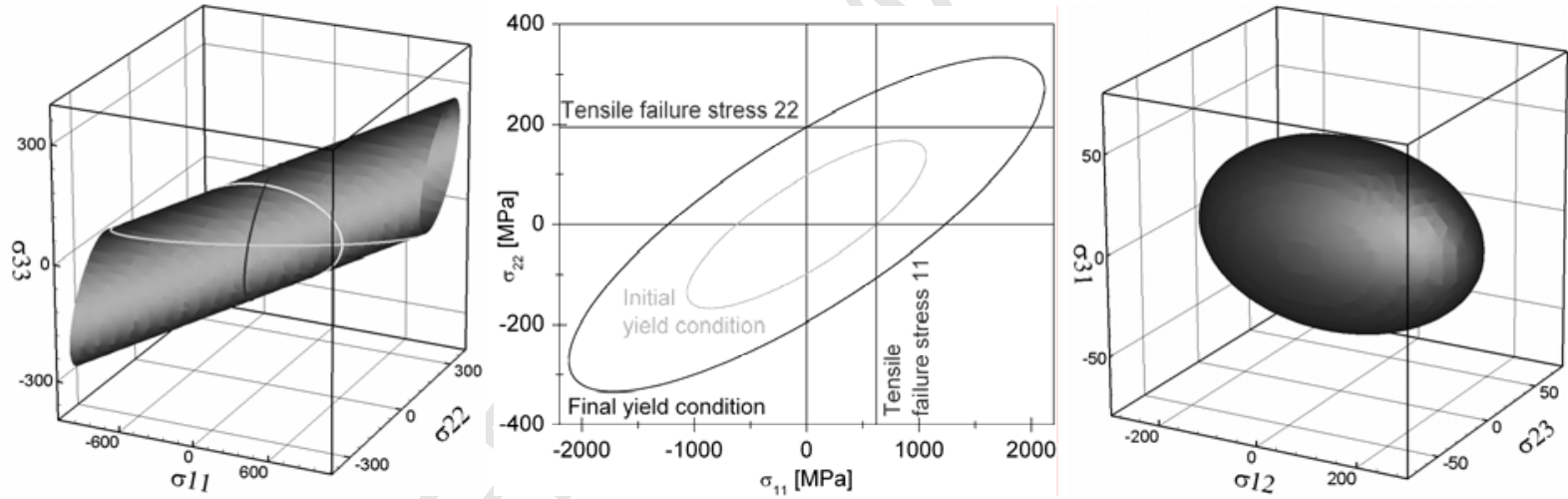

Fig. 5. Plots of the yield condition. Left: Initial yield surface in normal stress space. Middle: Cross-sections in the $\sigma_{11^{-}} \sigma_{22^{-}}$ plane. Right: Initial yield surface in shear stress space. All values are given in MPa. Note that different scales are used on the axes.

The yield surface in normal stress space is a closed but very elongated ellipsoid and only appears to be an open surface in the plotted region. With the new plasticity parameters all simulations remained stable. The stress state of the CFRP is defined by six independent variables. For each stress component, a failure value can be defined (three tensile failure stresses and three maximum shear stresses). After a failure stress is reached, linear softening can be modelled for each stress component by specifying a fracture energy. During the softening, damage is accumulated from 0 to 1 in the variables $D_{i j}$. The coupling of different failure modes is achieved by introducing three failure surfaces. As an example, the first one is given by 
Wicklein, et al. / International Journal of Impact Engineering

$$
\mathrm{e}_{11 \mathrm{f}}^{2}=\left(\frac{\sigma_{11}}{\sigma_{11, \text { fail }}\left(1-\mathrm{D}_{11}\right)}\right)^{2}+\left(\frac{\sigma_{12}}{\sigma_{12, \text { fail }}\left(1-\mathrm{D}_{12}\right)}\right)^{2}+\left(\frac{\sigma_{31}}{\sigma_{31, \text { fail }}\left(1-\mathrm{D}_{31}\right)}\right)^{2} \geq 1
$$

The damage variable $\mathrm{D}_{11}$ for the next time step $\mathrm{n}+1$ is then defined by

$$
\mathrm{D}_{11}^{\mathrm{n}+1}=\mathrm{D}_{11}^{\mathrm{n}}+\Delta \mathrm{D}_{11}+\mathrm{C}^{*} \cdot \Delta \mathrm{D}_{12}+\mathrm{C}^{*} \cdot \Delta \mathrm{D}_{31}
$$

where $C^{*}$ is the damage coupling coefficient, which can be chosen between 0 and 1 . With a value of 0 , the damage variable is uncoupled from the others. This allows, for example, to model the failure of the matrix in an out-of-plane shear test, while the fibres (in-plane) remain intact. In this study a value of 0.2 gave reasonable results. Furthermore, an 'orthotropic post failure option' was implemented, which describes the material as bulk failed (set pressure to zero) as soon as two of the damage variables of a failure surface have reached 1 . The complete data set derived in this study is summarised in Table 3 . Note that the off-diagonal coefficients of the stiffness matrix are being reduced as damage increases. This guarantees that straining in a direction that has already delaminated will not result in any stresses in the transverse directions.

\begin{tabular}{|c|c|c|c|c|c|}
\hline \multicolumn{2}{|c|}{ Equation of State: Ortho } & \multicolumn{2}{|c|}{$\begin{array}{c}\text { Strength: Orthotropic } \\
\text { Yield }\end{array}$} & \multicolumn{2}{|l|}{ Failure: Orthotropic Softening } \\
\hline Reference density $/ \mathrm{g} / \mathrm{cm}^{3}$ & 1.563 & A11 & 0.025 & Tensile Failure Stress 11 /MPa & 619 \\
\hline Young's Modulus 11 /GPa & 72.90 & A22 & & Tensile Failure Stress 22 /MPa & 195 \\
\hline Young’s Modulus 22 /GPa & 22.89 & A33 & 0.660 & Tensile Failure Stress 33 /MPa & 245.7 \\
\hline Young’s Modulus 33 /GPa & 9.07 & A12 & -0.1285 & Maximum Shear Stress 12 /MPa & 280.5 \\
\hline Poisson’s Ratio 12 & 0.77 & A13 & 0 & Maximum Shear Stress 23 /MPa & 39.0 \\
\hline Poisson's Ratio 23 & 0.55 & A23 & -0.473 & Maximum Shear Stress 31 /MPa & 47.5 \\
\hline Poisson’s Ratio 31 & 0.0187 & A44 & 3.157 & Fracture Energy $11 / \mathrm{J} / \mathrm{m}^{2}$ & $1 \mathrm{E}-6$ \\
\hline Shear Modulus 12 /GPa & 48.35 & A55 & 2.128 & Fracture Energy $22 / \mathrm{J} / \mathrm{m}^{2}$ & $1 \mathrm{E}-6$ \\
\hline Shear Modulus 23 /GPa & 0.558 & A66 & 0.061 & Fracture Energy $33 / \mathrm{J} / \mathrm{m}^{2}$ & 333.5 \\
\hline Shear Modulus 31 /GPa & 0.873 & $\bar{\sigma}_{\# 1} / \mathrm{MPa}$ & 120.025 & Fracture Energy $12 / \mathrm{J} / \mathrm{m}^{2}$ & $1 \mathrm{E}-6$ \\
\hline Bulk Modulus A1 /GPa & 25.04 & $\bar{\sigma}_{\# 10} / \mathrm{MPa}$ & 238.825 & Fracture Energy $23 / \mathrm{J} / \mathrm{m}^{2}$ & 1378 \\
\hline Parameter A2 /GPa & 0 & $\bar{\varepsilon}^{p_{\# 1}}$ & 0 & Fracture Energy $31 / \mathrm{J} / \mathrm{m}^{2}$ & 747 \\
\hline Parameter A3 /GPa & 0 & $\bar{\varepsilon}^{\mathrm{p}_{\# 10}}$ & 0.00155 & Damage Coupling Coefficient & 0.2 \\
\hline Parameter B0 & 1.098 & & & & \\
\hline Parameter B1 & 1.098 & & & & \\
\hline Parameter T1 /GPa & 25.04 & & & & \\
\hline Parameter T2 /GPa & 0 & & & & \\
\hline
\end{tabular}

Table 3. Data set of the CFRP material model.

This data set is validated in the next two chapters by simulation of PPI and HVI tests. These tests were not used for the derivation of the model (except for tensile failure stress 33, B0, and B1 from the PPI), and the data set was not fitted to these tests (except for A2 and A3). Many different impact situations were used for the validation to guarantee a broad application range of this parameter set. 
Wicklein, et al. / International Journal of Impact Engineering

\section{Planar Plate Impact}

Spallation experiments, inverse impact tests, and multi shock tests (direct and inverse) were conducted with different plate thicknesses and impact velocities (Table 4). From the spallation signals (Fig. 6, left) an average failure tensile stress $\sigma_{33 \text {,fail }}$ of $245.7 \mathrm{MPa}$ was derived. It was found that $\sigma_{33 \text {,fail }}$ decreases with increasing impact velocity in the investigated regime. All PPI tests were simulated with ANSYS AUTODYN under a 1D state of strain in the impact direction. The cell size of the finite elements was $0.02 \mathrm{~mm}$. In general, good agreement was found between the simulations and the measurements (also for the multi shock tests, which are not shown). To be precise, the acoustic sound speed in orthotropic directions is exactly reproduced whereas the shock propagation, as a consequence of both the modelling approach and the experimental characterisation strategy, is only an approximation. Although pressure contributions from deviatoric strain components are contained, the directional dependency of shock propagation is not part of the existing modelling technique. A theory for the direct derivation of the coefficients in the polynomial EOS, coupled with orthotropic response, is currently not available. Calibration of at least four constants $\left(A_{2}, A_{3}, B_{0}, B_{1}\right)$ is required. This process may be impractical for matching a large number of experimental PPI test results. To avoid this calibration exercise here, the isotropic assumption of $\mathrm{B}_{0}=\mathrm{B}_{1}=\Gamma=2 \mathrm{~S}-1$ has been applied. Only $\mathrm{A}_{2}$ and $\mathrm{A}_{3}$ were calibrated to the experimental results.

Table 4. PPI tests conducted with CFRP. The setup describes the composition of the projectile and target plates.

\begin{tabular}{|c|c|c|c|}
\hline Test type & Setup & Velocity $[\mathrm{m} / \mathrm{s}]$ & Test no. \\
\hline \multirow[t]{7}{*}{ Spallation } & $2.98 \mathrm{~mm} \mathrm{Al} \rightarrow 6.24 \mathrm{~mm} \mathrm{CFRP}$ & 683 & 2950 \\
\hline & $2.96 \mathrm{~mm} \mathrm{Al} \rightarrow 6.26 \mathrm{~mm} \mathrm{CFRP}$ & 173 & 2951 \\
\hline & $2.98 \mathrm{~mm} \mathrm{Al} \rightarrow 6.46 \mathrm{~mm} \mathrm{CFRP}$ & 418 & 2961 \\
\hline & $2.95 \mathrm{~mm} \mathrm{Al} \rightarrow 6.16 \mathrm{~mm} \mathrm{CFRP}$ & 598 & 2962 \\
\hline & $2.98 \mathrm{~mm} \mathrm{Al} \rightarrow 6.42 \mathrm{~mm} \mathrm{CFRP}$ & 1073 & 2963 \\
\hline & $3.00 \mathrm{~mm} \mathrm{Al} \rightarrow 6.40 \mathrm{~mm} \mathrm{CFRP}$ & 159 & 2992 \\
\hline & $3.00 \mathrm{~mm} \mathrm{Al} \rightarrow 6.40 \mathrm{~mm} \mathrm{CFRP}$ & 297 & 2993 \\
\hline \multirow{4}{*}{$\begin{array}{l}\text { Inverse } \\
\text { impact }\end{array}$} & $5.00 \mathrm{~mm} \mathrm{Al}+6.26 \mathrm{~mm} \mathrm{CFRP} \rightarrow 1.94 \mathrm{~mm} \mathrm{Cu}$ & 666 & 2948 \\
\hline & $4.95 \mathrm{~mm} \mathrm{Al}+6.50 \mathrm{~mm} \mathrm{CFRP} \rightarrow 1.98 \mathrm{~mm} \mathrm{Cu}$ & 1000 & 2949 \\
\hline & $4.99 \mathrm{~mm} \mathrm{Al}+6.26 \mathrm{~mm} \mathrm{CFRP} \rightarrow 2.00 \mathrm{~mm} \mathrm{Cu}$ & 231 & 2952 \\
\hline & $4.99 \mathrm{~mm} \mathrm{Al}+6.07 \mathrm{~mm} \mathrm{CFRP} \rightarrow 2.02 \mathrm{~mm} \mathrm{Cu}$ & 470 & 2959 \\
\hline \multirow{6}{*}{$\begin{array}{l}\text { Multi } \\
\text { shock }\end{array}$} & $7.96 \mathrm{~mm} \mathrm{Cu}+1.19 \mathrm{~mm} \mathrm{CFRP} \rightarrow 7.99 \mathrm{~mm} \mathrm{Cu}$ & 695 & 2953 \\
\hline & $7.98 \mathrm{~mm} \mathrm{Cu} \rightarrow 1.18 \mathrm{~mm} \mathrm{CFRP}+8.00 \mathrm{~mm} \mathrm{Cu}$ & 725 & 2954 \\
\hline & $5.00 \mathrm{~mm} \mathrm{Cu}+1.20 \mathrm{~mm} \mathrm{CFRP} \rightarrow 4.99 \mathrm{~mm} \mathrm{Cu}$ & 908 & 2955 \\
\hline & $5.00 \mathrm{~mm} \mathrm{Cu} \rightarrow 1.18 \mathrm{~mm} \mathrm{CFRP}+4.98 \mathrm{~mm} \mathrm{Cu}$ & 938 & 2956 \\
\hline & $7.98 \mathrm{~mm} \mathrm{Cu} \rightarrow 1.17 \mathrm{~mm} \mathrm{CFRP}+7.96 \mathrm{~mm} \mathrm{Cu}$ & 549 & 2957 \\
\hline & $4.98 \mathrm{~mm} \mathrm{Cu} \rightarrow 1.14 \mathrm{~mm} \mathrm{CFRP}+4.99 \mathrm{~mm} \mathrm{Cu}$ & 604 & 2958 \\
\hline
\end{tabular}

The results for spallation and inverse impact are depicted in Fig. 6. The circumstances outlined above are reflected in the following results: With increasing impact velocity, the spallation simulations underestimate the surface velocities from the tests, especially for test 2963. For the inverse impact, the times of the backing reflections (e.g. $3000 \mathrm{~ns}$ for test 2949) are overestimated. Nevertheless, a 
Wicklein, et al. / International Journal of Impact Engineering

satisfying degree of validation was achieved.
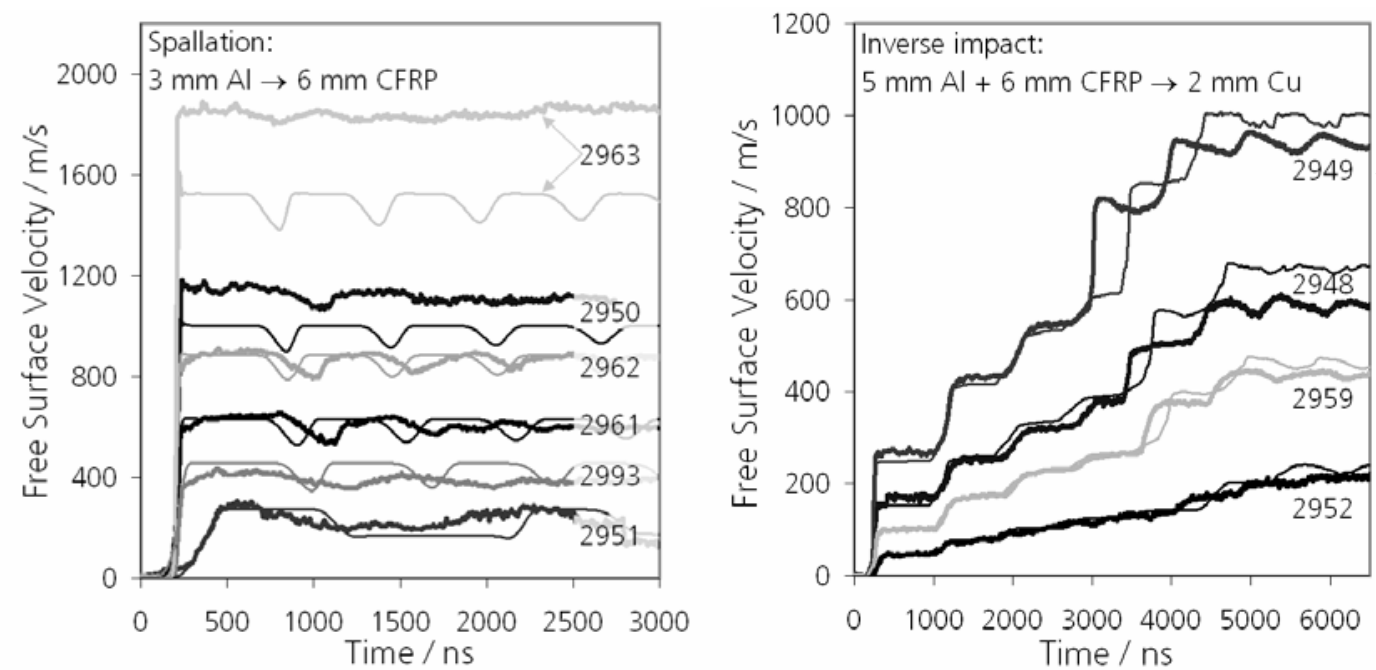

Fig. 6. Measured (thick lines) and simulated (thin lines) free surface velocities for spallation and inverse impact.

\section{Hypervelocity Impact}

Altogether, 8 impact tests were performed featuring two different configurations (normal impact without HC, oblique with HC). The samples were mounted on witness plates made of $\mathrm{Al} 7075$ with a stand-off of $100 \mathrm{~mm}$. The sample sizes were $100 \mathrm{~mm}$ x $100 \mathrm{~mm}$ for the normal and $150 \mathrm{~mm}$ x $100 \mathrm{~mm}$ for the oblique shots. An overview of the tests is given in Table 5. The sample orientation for the oblique impacts was chosen in such a way that the 1-direction of the CFRP was always perpendicular to the shot axis. The projectile velocity was measured with two laser light barriers. For the case that the second barrier would not trigger two backup systems were applied. An optic sensor detected the impact flash and therefore allowed to measure the impact time and derive the projectile velocity. The impact flash is not as easily detected for CFRP compared with aluminium; therefore an acoustic sensor was used as secondary backup system. The tests were recorded with a high speed framing camera. The projectiles consisted of Al 99.98\% or Al 2017-T4 depending on the diameters available.

In order to provide a good validation basis from the tests, the impact conditions should result in a distinct but not catastrophic damage. This can be achieved when testing close to the ballistic limit. Thus, the SRL ballistic limit equation and numerical simulations of the impacts applying a predictive material model data set were considered. The procedure of deriving a predictive, theoretical CFRP material model for HVI is described in detail in [20].

In the following, the experimental and numerical results of one impact for each of the two configurations will be described (tests 236 and 4848, both close to the ballistic limit). In the normal impact of test 236, a roughly circular perforation hole and surface spallation running in 1-direction could be found on the front face sheet (Fig. 7). No spallation occurred on the rear side; however there were small cracks and bulging. 
Wicklein, et al. / International Journal of Impact Engineering

Table 5. HVI tests conducted in this study. The results are shown both as symbols with regard to the ballistic limit and as short descriptions.

\begin{tabular}{|c|c|c|c|c|c|}
\hline Test typ & $\begin{array}{c}\text { Projectile } \\
\text { density } \\
{\left[\mathrm{g} / \mathrm{cm}^{3}\right]}\end{array}$ & $\begin{array}{c}\text { Projectile } \\
\text { velocity } \\
{[\mathrm{km} / \mathrm{s}]}\end{array}$ & $\begin{array}{c}\text { Projectile } \\
\text { diameter } \\
{[\mathrm{mm}]}\end{array}$ & $\begin{array}{c}\text { Test } \\
\text { no. }\end{array}$ & Result \\
\hline I & 2.8 & 2.915 & 0.961 & 231 & Perforation \\
\hline & 2.8 & 4.577 & 0.782 & 235 & No visually noticeable \\
\hline & 2.8 & 4.935 & 1.179 & 236 & $\begin{array}{l}\text { At ballistic limit (= } \\
\text { borderline } \\
\text { detachment/cracks/minimal } \\
\text { perforation) }\end{array}$ \\
\hline & 2.7 & 2.934 & 2.446 & 4853 & $\geq \quad$ At ballistic limit \\
\hline & 2.7 & 6.137 & 1.553 & 4847 & $<\quad$ No visually noticeable \\
\hline $60^{\circ}$ & 2.7 & 6.095 & 1.775 & 4848 & At ballistic limit \\
\hline & 2.7 & 6.283 & 2.040 & 4849 & Perforation \\
\hline & 2.7 & 6.408 & 3.947 & 4851 & Significant perforation \\
\hline
\end{tabular}

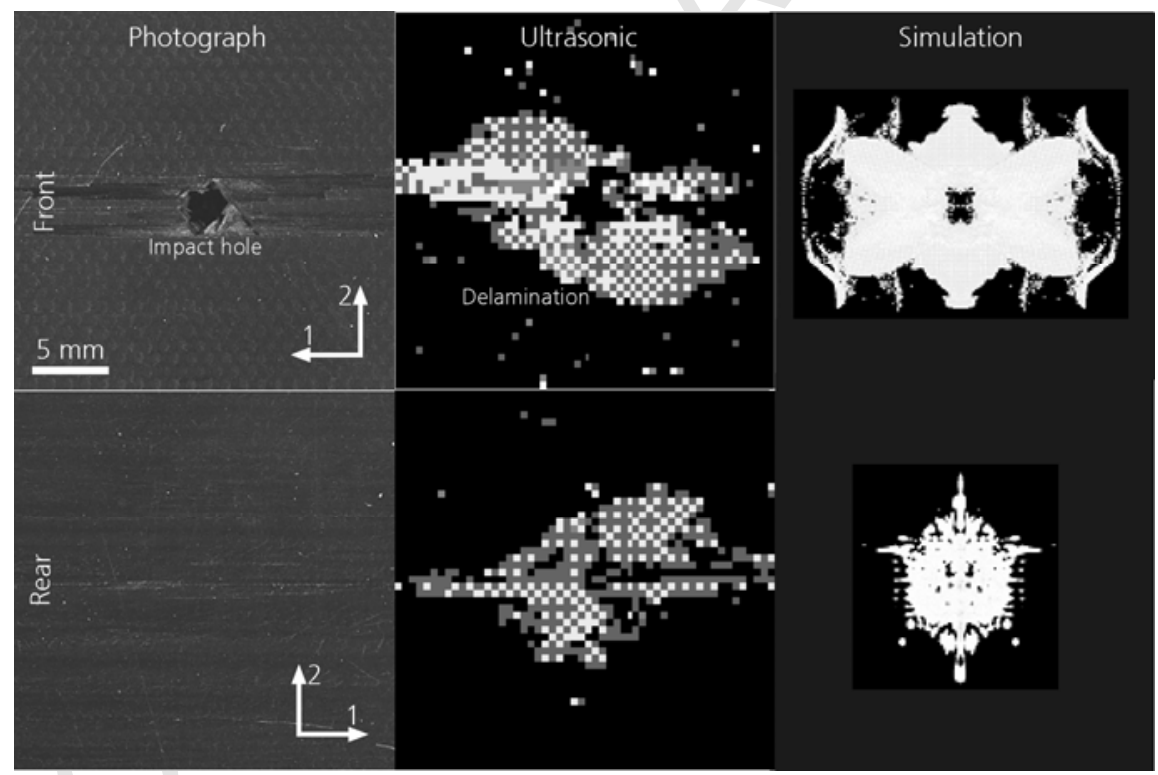

Fig. 7. Photographs, ultrasonic scans, and simulation (at $\mathrm{t}=26 \mu \mathrm{s}$ ) results of the normal impact test 236 for the front and rear CFRP sheets. The same scale is used in all pictures.

Cracks were also visible in the 1-direction. For the oblique shot 4848 an oval shaped perforation hole, minimum surface spallation, and cracking in 1-direction were found on the front sheet (Fig. 8). On the rear side only small cracks and some bulging were observed. In both experiments, delamination within the CFRP was detected with much larger extension than the visually noticeable damage. Table 6 
quantifies the damage in the structures.

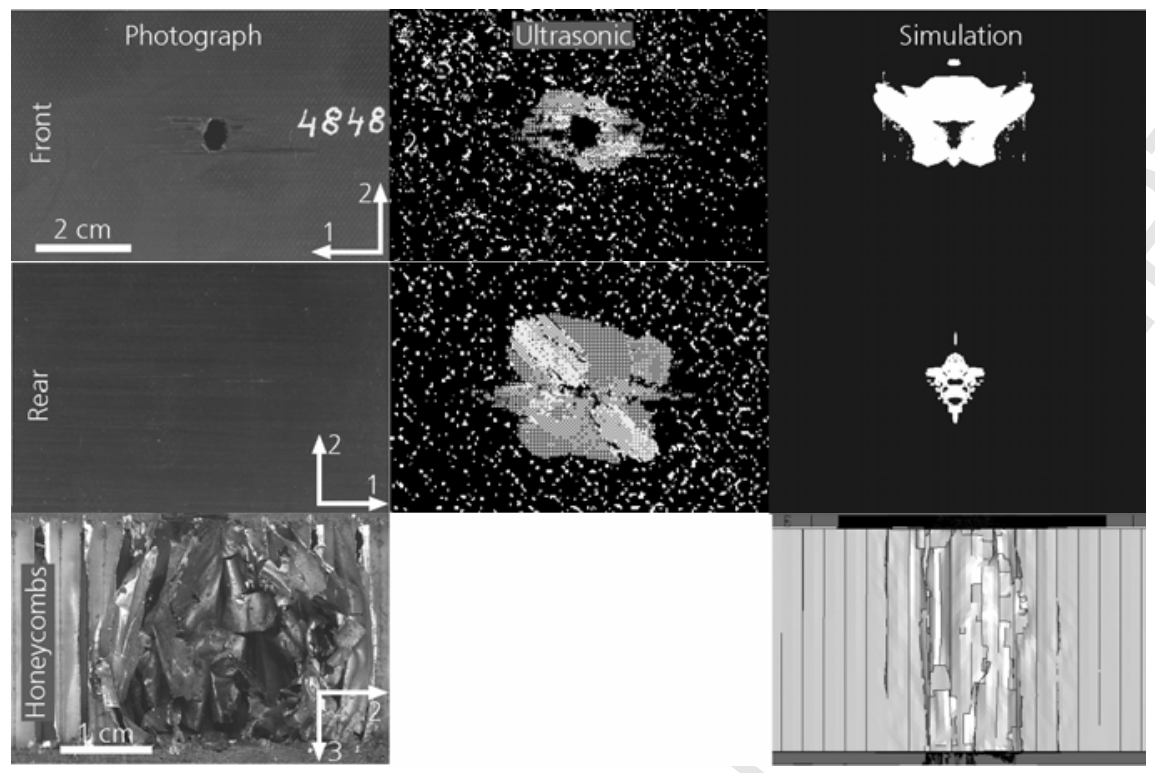

Fig. 8. Comparison of experimental and numerical (at $\mathrm{t}=22.5 \mu \mathrm{s}$ ) damage for the front sheet, rear sheet, and the HC core.

Table 6. Damage in the CFRP and honeycombs for the normal and oblique impact. Simulated and measured values are shown. The numbers represent the maximum extension in each direction including cracks.

\begin{tabular}{lccccccc}
\hline & \multicolumn{2}{c}{ Clear hole front } & \multicolumn{2}{c}{ Delamination front } & \multicolumn{2}{c}{ Delamination rear } & Max. diameter HC \\
& $d_{h, 1}$ & $d_{h, 2}$ & $D_{D L, 1}$ & $D_{D L, 2}$ & $D_{D L, 1}$ & $D_{D L, 2}$ & $d_{H C}$ \\
\hline Exp. 236 & 3.02 & 3.07 & 39 & 14 & 29 & 13 & - \\
Sim. 236 & 2.6 & 3.1 & 19 & 18 & 14 & 18 & - \\
& & & & & & & \\
Exp. 4848 & 5.31 & 6.95 & 40 & 15 & 53 & 33 & 22 \\
Sim. 4848 & 7.2 & 6.0 & 35 & 19 & 13 & 14 & 11 \\
\hline
\end{tabular}

For the numerical simulations of the impact tests, an appropriate discretization is needed. Sensitivity studies were conducted to find the optimum mesh resolution. The sandwich was discretized in half-symmetry. In order to model the large deformations at the impact location, SPH particles were used (10 particles over face sheet thickness; for normal impact 18 particles due to the small projectile sizes). As the SPH approach is numerically expensive, volume elements joined to the SPH region (30 mm x $15 \mathrm{~mm}$ ) were applied for the CFRP further away from the impact for the $60^{\circ}$-simulations. No volume elements were joined to the SPH region $(20 \mathrm{~mm} \times 10 \mathrm{~mm})$ in the normal impacts as this would have resulted in too many elements. The number of volume elements in the front face sheet of the sandwiches was decreased by transition volume elements as shown in Fig. 9. The HC walls were discretized with shell elements (4 shells over cell wall). For the rear CFRP face sheet volume elements with grade zoning were utilised resulting in a finer mesh close to the impact channel. The simulations were run in parallel on 4 CPUs with an efficiency of 50\%.

The results of the simulations are included in Fig. 7, Fig. 8, and Table 6. The simulation plots of the front and rear face sheets show the area where the effective plastic strain is at least $0.155 \%$. This was 
the largest effective plastic strain measured in the tests (see Table 3) before complete failure occurred. Keeping in mind that plastic deformations in the simulations can correspond to microcracks and damage on the microscale in reality, the plotted regions can be considered as minimum extensions of the damaged areas in the simulations. They can be compared to the delamination areas from the ultrasonic tests. The agreement concerning the size of these areas for the front face sheets is satisfying for both the normal and oblique impact, although the shapes of the areas are different in both cases. Note that the simulation approach does not distinguish between different plies, as the material model is homogenised over the face sheet thickness. On the rear walls the damage in the simulations is smaller, especially in the oblique impact. The latter can be explained by an underestimation of damage of the HC cell walls (Fig. 8), which leads to increased channelling in the simulations. For the HC aluminium model, literature data was used. Experimental characterisation of the cell walls under dynamic loading could improve simulation results in further studies.

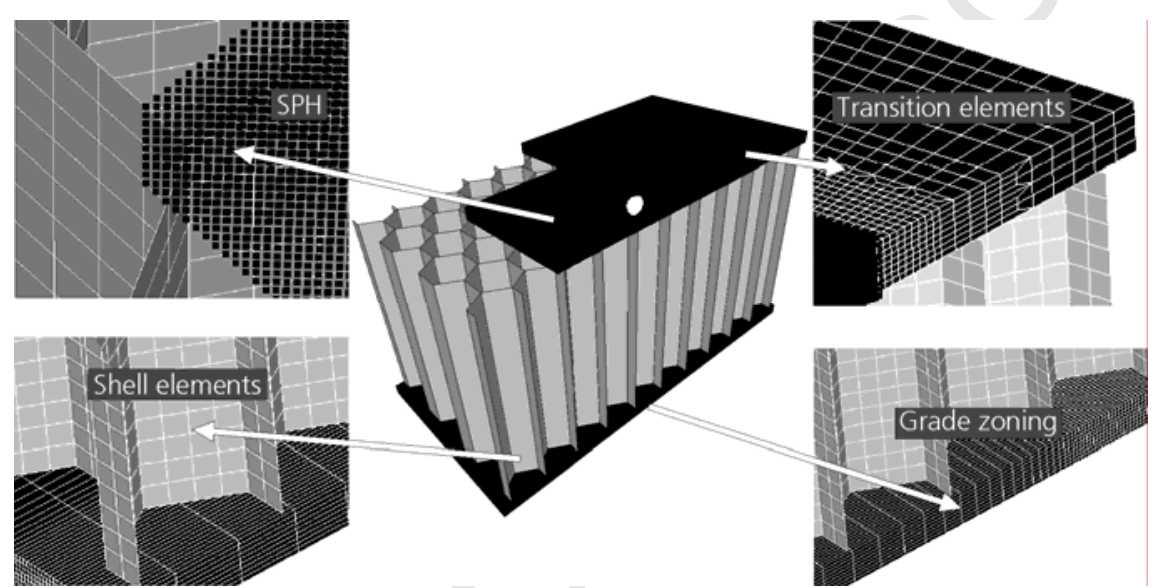

Fig. 9. Discretisation of the CFRP-Al/HC. Shell elements, volume elements, and SPH particles are being applied.

\section{Conclusions}

In this work a material model for CFRP, which is representative for satellite wall structures, was developed and validated by comparing numerical simulations to planar plate impact and hypervelocity impact tests. The results offer good agreement between simulations and experiments. Extensions of the existing material models - such as the damage coupling coefficient and further understanding of the restrictions on the plasticity parameters - have been implemented and documented. A complete data set derived from CFRP characterisation tests is specified. It can be used for impact simulations with ANSYS AUTODYN when an orthotropic continuum modelling approach is chosen.

\section{Outlook}

For further improvements of the simulation results the following issues can be addressed:

- Strain rate dependent material parameters. Most characterisation tests were conducted under quasistatic loading, while the impact velocities in the HVI tests reached $6 \mathrm{~km} / \mathrm{s}$. It is known in 
Wicklein, et al. / International Journal of Impact Engineering

literature, that the strength of CFRP can depend on strain rate. In this study, this was also proved for the spallation strength. Extensions to experimental characterisation techniques and material models to allow better representation of rate effects in composite materials is recommended.

- New methodology for the experimental identification of Hugoniot states and for the stress tensor decomposition, both of it with regard to the material's anisotropy. This could give better agreement of shock wave propagation in the individual directions of the orthotropic material.

- Stiffness values dependent on loading history. This could for example include the degradation of stiffness during plastic deformation or damage accumulation.

- Finally, a deeper understanding of the mechanical behaviour of CFRP on the microscale and its effects on the macroscale could improve continuum modelling approaches - for example to better correlate ultrasonic damage measurements to predictions of the simulations.

\section{Acknowledgements}

This work was funded by ESA/ESTEC under contract 18763/04/NL/SFe. The authors gratefully acknowledge the direction and advice of Michel Lambert of ESA/ESTEC. Additionally, the authors would like to thank Hartwig Nahme, Werner Riedel, Holger Voss, Frank Schaefer, and Composite Impulse GmbH \& Co, who also contributed to this work.

\section{References}

[1] Riedel W, Harwick W, White DM, Clegg RA. ADAMMO - Advanced Material Damage Models for Numerical Simulation Codes. ESA CR(P) 4397, EMI report I 75/03, Freiburg, October 31, 2003.

[2] Riedel W, Nahme H, White DM, Clegg RA. Hypervelocity impact damage prediction in composites: Part II-experimental investigations and simulations. International Journal of Impact Engineering, 2006; 33: 670-680.

[3] Hiermaier S, Riedel W, Hayhurst C, Clegg RA, Wentzel C. AMMHIS - Advanced Material Models for Hypervelocity Impact Simulations, Final Report, EMI Report E 43/98, ESA CR(P) 4305, Freiburg, July 30, 1999.

[4] White DM, Wicklein M, Clegg RA, Nahme H. Multi-layer insulation material models suitable for hypervelocity impact simulations. Accepted for publication in the International Journal of Impact Engineering.

[5] White DM, Taylor EA, Clegg RA. Numerical simulation and experimental characterization of direct hypervelocity impact on a spacecraft hybrid carbon fibre/Kevlar composite structure. International Journal of Impact Engineering, 2003; 29(1-6): 779 - 790.

[6] Chen JK, Allahdadi FA, Carney TC. High-velocity impact of graphite/epoxy composite laminates. Composite Science and Technology, 1997; 57: 1369-1379.

[7] Riedel W, Thoma K, Kurtz A, Collins P, Greaves L. Vulnerability of composite aircraft components to fragmenting warheads - Experimental Analysis, Material Modeling And Numerical Studies. 20th International Symposium On Ballistics, Orlando, Fl, 23-27 September 2002.

[8] Fujii K, Aoki M, Kiuchi N, Yasuda E, Tanabe Y. Impact Perforation behavior of CFRPs using high-velocity steel sphere. International Journal of Impact Engineering, 2002; 27(5): 497-508.

[9] Thissell WR, Zurek AK, Addessio F. Mechanical properties and failure mechanisms of carbon fiber reinforced epoxy laminated composites. Shock Compression of Condensed Matter, Seattle, Washington 
Wicklein, et al. / International Journal of Impact Engineering

August 13-18 1995.

[10] Nagao Y, Kibe S, Daigo K, Francesconi A, Pavarin D. Hypervelocity impact studies simulating debris collision on composite material. Proceedings of the 4th European conference on Space Debris, Darmstadt, Germany, 18-20 April 2005.

[11] Shintate K, Sekine H. Numerical simulation of hypervelocity impacts of a projectile on laminated composite plate targets by means of improved SPH method. Composites: Part A, 2004; 35: 683-692.

[12] Taylor EA, Herbert MK, Vaughan BAM, McDonnell JAM. Hypervelocity impact on carbon fibre reinforced plastic / aluminum honeycomb: comparison with Whipple bumper shields. International Journal of Impact Engineering, 1999; 23(1): 883-893.

[13] Schaefer F, Ryan S. Composite materials impact damage analysis, ESA Contract 16721/02/NL/CK - Final Report.

[14] Ryan S, Riedel W, Schaefer F. Numerical study of hypervelocity space debris impacts on CFRP/AL honeycomb spacecraft structures. International Astronautical Congress, Vancouver, (2004).

[15] Anderson Jr. CE, Cox PA, Johnson GR, Maudlin PJ. A constitutive formulation for anisotropic materials suitable for wave propagation computer programs-II. Comp. Mech., 1994; 15: 201-223.

[16] Chen JK, Allahdadi FA, Sun CT. A quadratic yield function for fiber-reinforced composites. Journal of Composites Materials, 31(8) (1997) 788-811.

[17] Faraud M, Destefanis R. Composite Materials Impact Damage Analysis (ESA contract 16721/02/NL/CK), WP 2100 'Identification of Composite Materials in Spacecraft” (2004), Contribution to TN 1.

[18] Wicklein M: CARMHIS - CFRP Material Models for Hypervelocity Impact Numerical Simulations Testing - Technical Note on WP 6000. EMI-report I-73/06, Freiburg, December 2006.

[19] Clegg RA, White DM, Riedel W, Harwick W. Hypervelocity impact damage prediction in composites: Part I-material model and characterisation. International Journal of Impact Engineering, 2006; 33: 190-200.

[20] Ryan S, Riedel W. Preliminary theoretical material characterization for numerical modeling of composite structures. Proc. 56th International Astronautical Congress, Oct. 2.-6. 2005, Fukuoka, Japan, IAC-05C2.5.10. 